Original Research

\title{
Spatio-Temporal Differentiation Characteristics and Determinants of Coupling Coordination Degree in Technological Innovation-Industrial Upgrading-Ecological Environment System: a Case Study of Jiangsu Province, China
}

\author{
Xueguo Xu, Yanfei Zhou* \\ School of Management, Shanghai University, Shanghai 200444, China
}

Received: 8 September 2020

Accepted: 27 November 2020

\begin{abstract}
During the past few years, the accelerating development of economy has caused great crisis on ecological environment. The scarcity of natural resources and deterioration of environment exert harmful influence on regional sustainable development. This study aims to find the method to realize the regional coordinated development from the perspective of technological innovation (TI), industrial upgrading (IU) and ecological environment (EE) as well as their interactions. The coupling coordination model is applied to calculate the coupling coordination degree (CCD) in technological innovationindustrial upgrading-ecological environment system (TIES). Additionally, the geo-detector, a robust spatial statistics approach, is used to explore the determinants of CCD. It is found that the level of CCD is in the stage of mild imbalance during the study period. In terms of time series, it presents a slight growth with fluctuation from 0.329 to 0.354 . Spatially, southern Jiangsu is in the mild imbalance stage and the coupling coordination characteristic transforms from "IU lagged" to "EE lagged". Conversely, middle and northern Jiangsu are basic imbalance with "TI lagged". We also find that the superposition of two factors in TIES can obtain a "enhance, bilinear" even "enhance, nonlinear" effect.
\end{abstract}

Keywords: TIES, coupling and coordination, spatio-temporal differentiation, geo-detector, Jiangsu Province

\section{Introduction}

An increasing demographic, exponential economy and the exploitation of resources have intensified the

*e-mail: zyfyibuduo@126.com

ecological environment problems during the past few years in China. At present, the environmental pollution is mainly manifested in high discharge of three wastes (waste gas, waste water, and waste residue) [1], which severely restrains the regional sustainable development. For a quite long time, the economy of Jiangsu Province (one of the developed provinces in 
China) has been ranking in the forefront of China. In 2019, the GDP of the region reached 99,631.5 billion CNY, which accounted for $10.06 \%$ of China's GDP [2]. However, the excellent economic performance causes huge amounts of energy consumption and aggravates the emission of pollutants simultaneously. The low efficiency of economic development results in overexploitation of resources, such as oil, gas and forests [3]. The ecological environmental problems become increasingly serious. According to the secondlevel standard of "Environmental Air Quality Standard" (GB3095-2012), the annual evaluation showed that the air quality of each city in Jiangsu Province did not reach the standard. The discharge of pollutants (i.e., $\mathrm{PM}_{2,5}$, $\mathrm{PM}_{10}, \mathrm{O}_{3}$ and $\mathrm{NO}_{2}$ ) is large in quantity and wide in scope and exceeds the standard. Besides, there were 41 days for heavy pollution weather warning. The average incidence of acid rain was $12.1 \%$ and the average annual precipitation $\mathrm{pH}$ value was 5.69. Nine of the 13 cities have monitored acid rain pollution in different degrees [4]. Meanwhile, several enterprises in backward technology still maintain the "resource-based economic growth" model. The idea of "treatment after pollution" is fundamentally unchanged, the unreasonable "high investment, low output" situation still exists. In order to relieve this contradiction, translate the economy from "high-speed growth" to "high-quality development", Chinese government put forward the concepts of "innovation, coordination, green, opening and sharing" development and launches a strategy for construction of ecological civilization cities. Thus, the traditional aggressive economic growth model ought to be abandoned. In the light of the pollutants emitted by production activities in China are far higher than those emitted by daily life and natural process, production is the main object for solving environmental problems [5]. Green technological innovation is necessary not only to improve the productivity of industries, but also to enhance the environmental benefits of reuse, recovery, and recycling [6]. At the same time, industrial upgrading can effectively reduce the resource consumption and pollution emissions of industrial production. With the pressure from resource exhaustion and environmental deterioration, how to achieve green, coordinated and sustainable development has become an urgent problem for the government and academia in Jiangsu Province.

Due to the deterioration of environment, ecological protection and sustainable development have been an issue of great concern to the public. Many studies have discussed the factors that influence ecological environment such as economic development and urbanization. For instance, Wang et al. analyzed the coupling and coordinated relationship between social economy and energy environment [7]. Cui et al. discussed the relationship of coupling coordination between social economy and water environment [8]. Dong et al. explored the drivers of the decoupling indicator between economic growth and energy-related $\mathrm{CO}_{2}$ from the perspectives of decomposition and spatiotemporal heterogeneity [9]. Yang et al. evaluated the dynamic coupling relationship between agricultural economy and agroecological environment [10]. Xu et al. explored the overall coordination relationship between economy and ecological environment systems based on the Lotka-Volterra coordination degree model [11]. In addition, there are some evidences of the relationship between ecological environment and urbanization. As an example, Yao et al. discussed the coupling relationship between new urbanization and ecological-environmental stress [12]. Ding et al. analyzed the relationship between urbanization and the air environment [13]. Fang et al. concluded the interactive coupling theory on urbanization and the eco-environment in mega-urban agglomerations [14]. Wang et al. explored the coordination of urbanization and ecological environment composite system and its dominant factors [15]. Liu et al. analyzed the temporal and spatial characteristics of the coordination of urbanization and eco-environment [16].

Technological innovation is a vital guarantee and powerful way for the construction of ecological environment [17]. It has a significant positive effect on water utilization efficiency [18]. Besides, technological innovation can reduce $\mathrm{CO}_{2}$ emissions and contributes to facilitating economic growth [19]. Meanwhile, environmental regulation (ER) has different impacts on technological innovation, and there is a bidirectional causal relationship between them. Some literature suggests that ER is conducive to technological innovation. For instance, the "Porter Hypothesis" holds that appropriate ER can stimulate more innovative activities and simultaneously realize environmental performance and economic benefits [20]. ER significantly increases R\&D investment [21]. Also, the intensive $\mathrm{CO}_{2}$ emissions promote the level of renewable energy technological innovation [22]. On the contrary, some researchers point out that ER inhibits technological innovation. Such as regulations suppress innovation in firms because the deterministic nature of regulation limits their strategic choices [23]. In similar lines, ER increases the cost of enterprises and reduces the competitiveness of enterprises, which is not conducive to technological innovation [24]. Besides, the impact of ER on technological innovation depends on whether it brings enough innovation pressure to firms by the rising cost of compliance [25].

In addition, optimizing industrial structure is the object of government departments to strengthen macrocontrol, which contributes to ecological environment as well [26]. On one hand, industrial transformation and upgrading significantly reduce carbon emissions [27]. The adjustment and optimization of industrial structure decrease the overall environmental pollution and improve the situation of industrial source pollution [28]. On the other hand, the measure of industrial upgrading contributes to achieving a mutually beneficial balance between environmental protection and economic development [29]. Moreover, the relationship between 
the industrial structure and ecological environment has been the focus of discussion. For instance, the ecological environment and industrial spatial structure in Gansu Province interact with each other, which strengthens the regional differentiation and aggravates the vulnerability of ecological environment [30]. The interaction between ER and industrial structure has a positive impact on $\mathrm{PM}_{2.5}$ decoupling efforts (PDE), which verifies the existence of "Porter Hypothesis" [31]. The CCD between industrial structure and the ecoenvironment in Beijing shifts from "barely coordinated development" to "superior coordinated development" [32]. The feedback of water resource consumption drives the optimization and upgrading of industrial development patterns towards clean production through advanced technologies and investments [33].

Therefore, the discussions on ecological environment will be adopted from the perspectives of technological innovation and industrial structure. Technological innovation is the main way to realize industrial transformation and upgrading in developing countries [34]. It promotes the expansion of emerging industries and intensifies competition between old and new markets. Furthermore, it is conducive to industrial transformation and upgrading [35]. The economic effect of industrial upgrading mainly comes from the technological progress of intra-industry [36]. The resource-based cities promote transformation and upgrading of industries to consolidate the industrial foundation of city-industry integration through technological innovation [37]. The relevant research departments within firms need to improve the efficiency of research and development (R\&D) institutions so as to provide a solid foundation for innovation, transformation and upgrading of the manufacturing industry[38]. Technological innovation is the necessary path to achieve success in industrial transformation and upgrading [39].

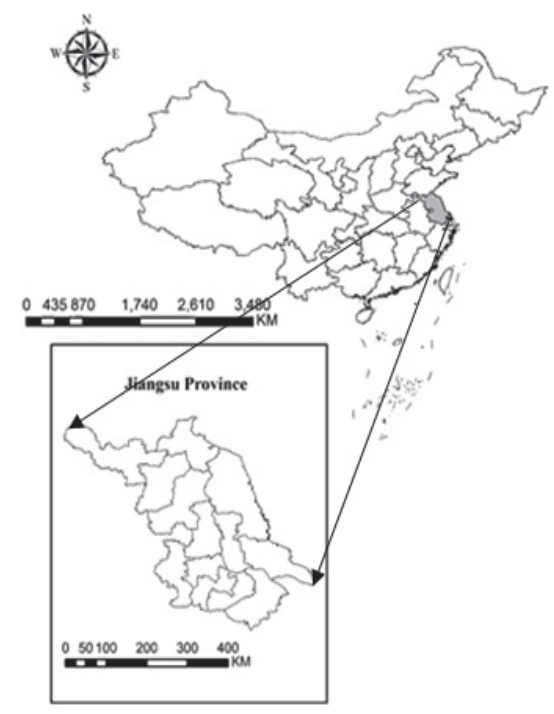

In comparison to previous literature, this study extends them from the following ways. (1) The existing literature on technological innovation, industrial upgrading and ecological environment tends to split the three subsystems. Hence, by constructing a coupling coordination model, this paper innovatively explores the interaction mechanism and determinants of CCD in TIES. (2) Additionally, this study forms a complete index evaluation system and reasonable mathematical model for the measurement of their interaction degree. (3) Due to the different characteristics in different regions, this research examines the spatio-temporal differentiation characteristics of technological innovation, industrial upgrading, ecological environment, as well as their CCD.

\section{Data and Materials}

\section{Study Area}

Jiangsu Province $\left(116^{\circ} 18^{\prime}-121^{\circ} 57^{\prime} \mathrm{E}, 30^{\circ} 45^{\prime}-35^{\circ} 20^{\prime} \mathrm{N}\right)$ is located in the core area of the eastern coast of China (Fig. 1). It has 13 prefecture-level cities. The volume, speed and strength of economy development in Jiangsu has always been in the forefront of China. It has entered a level similar to "middle and upper class" developed countries [40]. Nonetheless, the internal development of Jiangsu Province is extremely uncoordinated. Specifically, southern Jiangsu is known to be the most developed region due to its superior geographical advantages. It achieves the highest level of regional economic development, followed by middle Jiangsu and northern Jiangsu.

\section{Data Sources}

The original data for the indicators are obtained from the Statistical Yearbook of Jiangsu Province

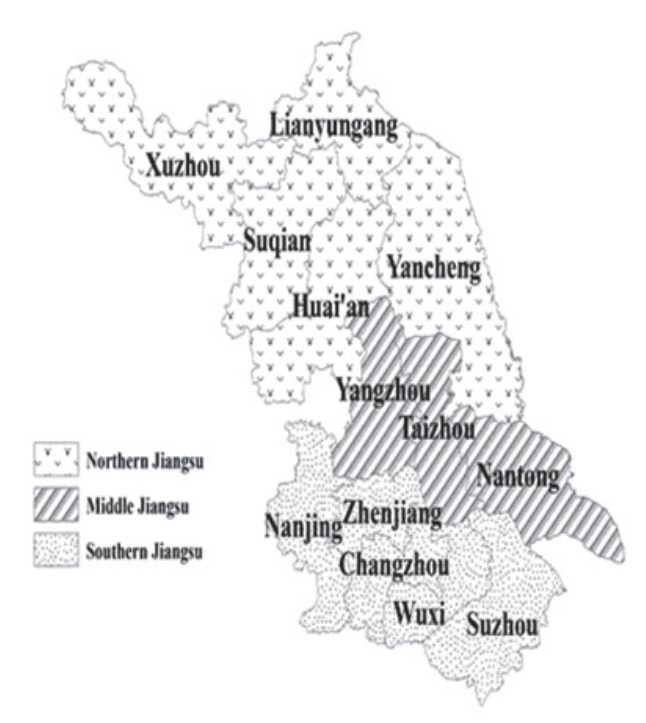

Fig. 1. Location overview of Jiangsu Province. 
(2010-2019) [41], the Statistical Bulletin of Jiangsu Province Economic and Social Development (2010-2019) [2], as well as the Environmental Statistics Bulletin of Jiangsu Province (2010-2019) [4]. The missing data are supplemented by the interpolation method of adjacent years in order to ensure the objectivity of data calculation and empirical analysis conclusions. To eliminate the influence of different indicators' magnitude and dimension, we standardize the data using equations (1) and (2) [42].

$$
X_{i j}=\frac{a_{i j}-\min \left\{a_{i j}\right\}}{\max \left\{a_{i j}\right\}-\min \left\{a_{i j}\right\}}, a_{i j} \text { is a positive indicator }
$$

$$
X_{i j}=\frac{\max \left\{a_{i j}\right\}-a_{i j}}{\max \left\{a_{i j}\right\}-\min \left\{a_{i j}\right\}}, a_{i j} \text { is a negative indicator }
$$

...where $X_{i j}$ denotes the original value of indicator $j$ in year $i ; a_{i j}$ denotes the standardized value; $\max \left\{a_{i j}\right\}$ and $\min \left\{a_{i j}\right\}$ indicate the maximum and minimum value of indicator $j$ for all years, respectively. Thus, $X_{i j} \in[0,1]$.

\section{Methodology}

\section{Coupling Model of TIES}

As can be seen in the Fig. 2, the coupling coordination relationship of TIES is illustrated, and specific performance is as follows. In terms of technological innovation, it includes two aspects: the continuous breakthrough of new technologies and the creation of new products. Strengthening technological innovation can improve the conversion efficiency between input and output, promote the adjustment and optimization of traditional industrial structure, convert the traditional industrial model from the source so as to promote industrial upgrading. At the same time, it can provide technical support for improving production

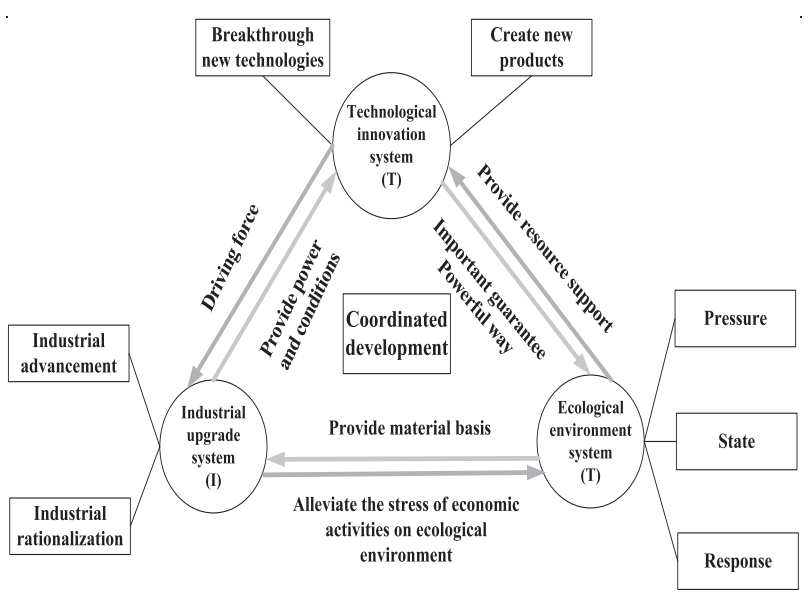

Fig. 2. Coupling coordination relationship of TIES. equipment, enhance the transmission efficiency in ecological environment system. Furthermore, it is conducive to increasing the supply capacity of ecological environment which is the material foundation of economic development.

From the view of measuring industrial upgrading, it includes two basic points, industrial structure advancement and industrial structure rationalization. The former refers to the continuous evolution of industrial structure to a higher level. It emphasizes that industrial structure can ensure the sustained growth of the national economy with intensiveness and coordination. While the latter means the rational allocation and effective transformation of economic factors within the industry. It attaches importance to plasticity, and industrial structure should adapt to social economy [27]. Industrial structure rationalization is conducive to the optimal allocation of resources. On the one hand, it emphasizes that different industries can get relatively reasonable support of factors of production and sufficient material and human supply, which provides power and conditions for technological innovation. On the other hand, it can reduce the pressure of ecological environment caused by economic activities to a large extent.

Ecological environmental system includes not only natural elements, but also combination of ecological relations between human beings and nature. Affluent ecological resources are the basic guarantee of social and economic development. Moreover, the resource elements of ecosystem provide material basis for industrial upgrading and determine the order and scale of industrial development. At the same time, the ecological environment has two impacts on technological innovation. One is that it provides resources for technological innovation. In addition, a good ecological environment is conducive to the introduction of talents, investment and high-tech industries. The other is that it impels the realization of technological innovation when in the stage of resource shortage.

In summary, due to the interaction, coercion and dependence among three subsystems, as well as the internal input and output of resources and energies, TIES is an open, dynamic and non-linear complex system from the perspective of system theory.

\section{Evaluation Index of TIES}

This study follows the principles of scientificity, systematicity and quantity, and adds several composite indexes to construct a more comprehensive evaluation index system of TIES. For technological innovation indicators, there are two factor layers of resource input and performance output. For industrial upgrading, three aspects including industrial structure rationalization, industrial structure optimization and economic benefits are selected. In terms of ecological environment, three factor layers and seven indicator layers are constructed 
Table 1. Comprehensive Evaluation Index System and Weight of TIES.

\begin{tabular}{|c|c|c|c|c|c|}
\hline System layer & Factor layer & Indicator layer & Units & $\begin{array}{l}\text { Indicator } \\
\text { properties }\end{array}$ & Weight \\
\hline \multirow{5}{*}{$\begin{array}{l}\text { Technological } \\
\text { innovation } \\
\text { system } \\
\text { (T) }\end{array}$} & \multirow{2}{*}{$\begin{array}{l}\text { Resource input of } \\
\text { technological innova- } \\
\text { tion }\left(T_{1}\right)\end{array}$} & $\begin{array}{l}\text { Full-time equivalent of R\&D personnel } \\
\qquad\left(\mathrm{T}_{11}\right)\end{array}$ & - & + & 0.096 \\
\hline & & $\begin{array}{l}\text { Internal expenditure of R\&D } \\
\text { funds }\left(T_{12}\right)\end{array}$ & $10^{8} \mathrm{CNY}$ & + & 0.060 \\
\hline & \multirow{3}{*}{$\begin{array}{l}\text { Performance output } \\
\text { of technological } \\
\text { innovation }\left(\mathrm{T}_{2}\right)\end{array}$} & Number of patent applications $\left(\mathrm{T}_{21}\right)$ & - & + & 0.084 \\
\hline & & Number of scientific papers $\left(\mathrm{T}_{22}\right)$ & - & + & 0.098 \\
\hline & & Sales revenue of new products $\left(\mathrm{T}_{23}\right)$ & $10^{8} \mathrm{CNY}$ & + & 0.061 \\
\hline \multirow{6}{*}{$\begin{array}{l}\text { Industrial } \\
\text { upgrading system } \\
\text { (I) }\end{array}$} & \multirow{2}{*}{$\begin{array}{l}\text { Industrial structure } \\
\text { rationalization } \\
\left(\mathrm{I}_{1}\right) \\
\end{array}$} & Improved Theil Index $(\mathrm{TL})\left(\mathrm{I}_{11}\right)$ & - & + & 0.067 \\
\hline & & Employment-output deviation $\left(\mathrm{I}_{12}\right)$ & $\%$ & + & 0.049 \\
\hline & \multirow{2}{*}{$\begin{array}{l}\text { Industrial structure } \\
\text { optimization } \\
\left(\mathrm{I}_{2}\right)\end{array}$} & $\begin{array}{l}\text { The ratio of the output value of the tertiary } \\
\left.\text { industry to the secondary industry(TS)( } \mathrm{I}_{21}\right)\end{array}$ & $\%$ & + & 0.056 \\
\hline & & $\begin{array}{l}\text { Advance coefficient of tertiary } \\
\text { industry }\left(I_{22}\right)\end{array}$ & - & + & 0.035 \\
\hline & \multirow[b]{2}{*}{ Economic benefits $\left(\mathrm{I}_{3}\right)$} & Per capita GDP $\left(\mathrm{I}_{31}\right)$ & $\mathrm{CNY}$ & + & 0.063 \\
\hline & & $\begin{array}{l}\text { Per capita disposable income of urban } \\
\text { households }\left(\mathrm{I}_{32}\right)\end{array}$ & $\mathrm{CNY}$ & + & 0.054 \\
\hline \multirow{7}{*}{$\begin{array}{l}\text { Ecological } \\
\text { environment } \\
\text { (E) }\end{array}$} & \multirow{3}{*}{$\operatorname{Pressure}\left(\mathrm{E}_{1}\right)$} & Industrial $\mathrm{SO}_{2}$ emissions $\left(\mathrm{E}_{11}\right)$ & $10^{4}$ ton & - & 0.022 \\
\hline & & $\begin{array}{l}\text { Industrial smoke(powder) dust } \\
\text { emissions }\left(\mathrm{E}_{12}\right)\end{array}$ & $10^{4}$ ton & - & 0.046 \\
\hline & & Industrial waste water emissions $\left(\mathrm{E}_{13}\right)$ & $10^{8}$ ton & - & 0.029 \\
\hline & \multirow{2}{*}{$\operatorname{State}\left(\mathrm{E}_{2}\right)$} & Per capita area of park green areas $\left(\mathrm{E}_{21}\right)$ & $\mathrm{m}^{2}$ & + & 0.095 \\
\hline & & Per capita housing construction area $\left(\mathrm{E}_{22}\right)$ & $\mathrm{m}^{2}$ & + & 0.032 \\
\hline & \multirow[b]{2}{*}{ Response $\left(\mathrm{E}_{3}\right)$} & Urban area green coverage rate $\left(\mathrm{E}_{31}\right)$ & $\%$ & + & 0.031 \\
\hline & & $\begin{array}{l}\text { Comprehensive utilization rate of } \\
\text { industrial solid waste }\left(\mathrm{E}_{32}\right)\end{array}$ & $\%$ & + & 0.026 \\
\hline
\end{tabular}

Note: '+'and'-'represent the positive and negative indicators respectively. The greater the positive indicator value is, the better the effect for the subsystems and vice versa.

based on P-S-R (pressure-state-response) model. The specific indicator system is shown in Table 1.

Among which, the composite indexes are explained as follows. First, the improved Theil index can effectively avoid the shortcomings of traditional structure deviation degree and operation of Theil index, and consider the relative importance of industry [43]. The formula is expressed as follows:

$$
T L=\sum_{i=1}^{n} \frac{Y_{i}}{Y} \ln \left(\frac{Y_{i}}{L_{i}} / \frac{Y}{L}\right)
$$

...where $Y_{i}$ is the output value of industry $i, L_{i}$ is the employment number of industry $i$, and $n$ is the number of industry departments. The value range is 0 to 1 , and the industrial structure is more unreasonable if the value of $T L$ is higher.

Second, employment-output deviation degree is the sum of absolute deviations between employment structure and output structure of three industries, which reflects the degree of difference between two structures [44]. The equation is as follows:

$$
P=\left|\frac{L_{1}}{L}-\frac{Y_{1}}{Y}\right|+\left|\frac{L_{2}}{L}-\frac{Y_{2}}{Y}\right|+\left|\frac{L_{3}}{L}-\frac{Y_{3}}{Y}\right|
$$

Third, the leading coefficient of the tertiary industry is a measure of the leading degree of the change of the tertiary industry structure relative to the overall economic change. Formulas are as follows:

$$
\begin{gathered}
E_{3}=\alpha_{3}+\left(\alpha_{3}-1\right) / V_{3} \\
V_{3}=\ln \left(G D P_{R}\right)-\ln \left(G D P_{B}\right)
\end{gathered}
$$

$E_{3}$ denotes the leading factor of the tertiary industry, which is the ratio of the share of the tertiary industry between the reporting and base period. $V_{3}$ represents the change value of the whole economic system. $G D P_{R}$ 
and $G D P_{R}$ denote the reporting and base period of GDP respectively. In this study, we chose 2008 as the base period.

In order to avoid the effect of dimensionalities of each indicator, the range standardization method is used to process the data. Then the weight of each index is obtained by the entropy weight method (Table 1). Based on linear weighted average method, we measure the system evaluation index of technological innovation (TI), industrial upgrading (IU) and ecological environment (EE) respectively. The formulas are expressed as follows:

$$
T I=\sum_{i=1}^{m} W_{j} X_{i j}, I U=\sum_{i=1}^{m} W_{j} Y_{i j}, E E=\sum_{i=1}^{m} W_{j} Z_{i j}
$$

...where $W$ is the weight obtained and $X_{i j}$ is the normalized value of each index.

\section{Establishment of the Coupling Coordination Model}

Coupling refers to the phenomenon where two or more systems influence each other through various interactions [12]. Fig. 2 illustrates that there are three sets of interaction in TIES. Based on the model of coupling coefficient in physics, the coupling model among three subsystems can be expressed as follows:

$$
C=3\left\{\frac{T E \times I U \times E E}{[T E+I U+E E]^{3}}\right\}^{1 / 3}
$$

...where $C$ is the coupling degree, $C \in[0,1]$. The systems are more coordinated if the $C$ value is higher, and vice versa. As the result of coupling degree cannot fully reflect the coordinated development level, the CCD is introduced. It is expressed by the formulas as follows:

$$
\begin{gathered}
C C D=\sqrt{C \times T} \\
T=\alpha T E+\beta I U+\delta E E
\end{gathered}
$$

...where $T$ is the comprehensive evaluation index of TIES. $\alpha+\beta+\delta=1, \alpha, \beta$ and $\delta$ are the undetermined coefficients of three subsystems respectively. We consider they are of the same importance, hence set $\alpha=\beta=\delta=1 / 3$. Based on the previous research [45-47], the CCD was classified into four types and eight subtypes. Coupling coordination characteristic indicates the comparative relationship among TI, IU and EE (as shown in Table 2). For instance, $T I>I U>E E$ means that the development of technological innovation is superior to industrial upgrading than ecological environment (EE lagged).

\section{Geo-Detector}

The geo-detector model is developed based on geographical spatial difference of strata [48]. It can analyze mechanisms relating to geographical phenomena and identify the decisive factors on such phenomena. This model is first applied to explore the influential geographical factors on endemic diseases. At present, it has been widely utilized in the research fields of social economy and environment. The principle is to divide the sample into different layers or sub regions and make a judgement about the spatial heterogeneity. If the sum of variance of each sub region is less than the total variance of the whole region, it means that there is heterogeneity of spatial stratification [49]. In this study, the factor detector

\begin{tabular}{|c|c|c|c|c|}
\hline D & Type & Subtype & Index comparison & Characteristic \\
\hline \multirow{2}{*}{$0.8 \sim 1$} & \multirow{3}{*}{$\begin{array}{c}\text { Good } \\
\text { coordination }\end{array}$} & \multirow{2}{*}{ High quality coordination } & $\mathrm{TI}>\mathrm{IU}>\mathrm{EE} / \mathrm{TI}>\mathrm{EE}>\mathrm{IU}$ & Good coordination with IU/EE lagged \\
\hline & & & $\mathrm{IU}>\mathrm{TI}>\mathrm{EE} / \mathrm{IU}>\mathrm{EE}>\mathrm{TI}$ & Good coordination with TI/EE lagged \\
\hline $0.7 \sim 0.79$ & & Moderate coordination & $\mathrm{EE}>\mathrm{TI}>\mathrm{IU} / \mathrm{EE}>\mathrm{IU}>\mathrm{TI}$ & Good coordination with TI/IU lagged \\
\hline \multirow{2}{*}{$0.6 \sim 0.69$} & \multirow{3}{*}{$\begin{array}{c}\text { Basic } \\
\text { coordination }\end{array}$} & \multirow{2}{*}{ Primary coordination } & $\mathrm{TI}>\mathrm{IU}>\mathrm{EE} / \mathrm{TI}>\mathrm{EE}>\mathrm{IU}$ & Basic coordination with IU/EE lagged \\
\hline & & & $\mathrm{IU}>\mathrm{TI}>\mathrm{EE} / \mathrm{IU}>\mathrm{EE}>\mathrm{TI}$ & Basic coordination with TI/EE lagged \\
\hline $0.5 \sim 0.59$ & & Barely coordination & $\mathrm{EE}>\mathrm{TI}>\mathrm{IU} / \mathrm{EE}>\mathrm{IU}>\mathrm{TI}$ & Basic coordination with TI/IU lagged \\
\hline \multirow{2}{*}{$0.4 \sim 0.49$} & \multirow{3}{*}{$\begin{array}{c}\text { Basic } \\
\text { imbalance }\end{array}$} & \multirow{2}{*}{ Adjacent imbalance } & $\mathrm{TI}>\mathrm{IU}>\mathrm{EE} / \mathrm{TI}>\mathrm{EE}>\mathrm{IU}$ & Basic imbalance with IU/EE lagged \\
\hline & & & $\mathrm{IU}>\mathrm{TI}>\mathrm{EE} / \mathrm{IU}>\mathrm{EE}>\mathrm{TI}$ & Basic imbalance with TI/EE lagged \\
\hline $0.3 \sim 0.39$ & & Mild imbalance & $\mathrm{EE}>\mathrm{TI}>\mathrm{IU} / \mathrm{EE}>\mathrm{IU}>\mathrm{TI}$ & Basic imbalance with TI/IU lagged \\
\hline \multirow{2}{*}{$0.2 \sim 0.29$} & \multirow{3}{*}{$\begin{array}{l}\text { Serious } \\
\text { imbalance }\end{array}$} & \multirow{2}{*}{ Moderate imbalance } & $\mathrm{TI}>\mathrm{IU}>\mathrm{EE} / \mathrm{TI}>\mathrm{EE}>\mathrm{IU}$ & Serious imbalance with IU/EE lagged \\
\hline & & & $\mathrm{IU}>\mathrm{TI}>\mathrm{EE} / \mathrm{IU}>\mathrm{EE}>\mathrm{TI}$ & Serious imbalance with TI/EE lagged \\
\hline $0 \sim 0.19$ & & Extreme imbalance & $\mathrm{EE}>\mathrm{TI}>\mathrm{IU} / \mathrm{EE}>\mathrm{IU}>\mathrm{TI}$ & Serious imbalance with TI/IU lagged \\
\hline
\end{tabular}
and interaction detector are used for analysis respectively.

Table 2. Coupling Coordination Grade Evaluation Criteria of TIES. 


\section{Factor Detector}

Factor detector can be applied to characterize the contributions of different factor $X$ to the dependent variable $Y$, that is, the verification of spatial heterogeneity of $Y$ in the geographical layer of each factor $X$. The $q$ value is evaluated by the relationship between the variance of dependent variable and global variance in each type of factors [50]. This relationship is expressed in Eq. (11),

$$
q=1-\frac{1}{N \sigma^{2}} \sum_{h=1}^{L} N_{h} \sigma_{h}^{2}
$$

...where $q$ is an index to measure the influence of each factor accounts for the spatial distribution of CCD. The area is stratified into $L$ stratums, denoted by $h=1, \ldots, L ; N$ and $N_{h}$ indicate the number of units in the entire region and subregion $h$ respectively [15]; $\sigma^{2}$ and $\sigma_{n}^{2}$ denote the variance of CCD for the units in the entire region and subregion $h$ respectively. The value range of $q$ is $[0,1]$, the larger the value of $q$, the greater influence of the factor on the spatial distribution of CCD.

\section{Interaction Detector}

The main idea that underlies the use of interaction detector is to identify whether the interaction between two or more factors on dependent variable $Y$ is significantly greater or less than that of a single factor, and whether the influence of these factors on $Y$ is independent. The evaluation steps are as follows: Firstly, the $q$ values of the factor $\mathrm{x} 1$ and $\mathrm{x} 2$ are calculated. Secondly, a new layer is obtained by superimposing the geographical layers or subregions where the two factors are located, that is, the new layer $(x 1 \cap \times 2)$ is formed after the interaction of factor $\mathrm{x} 1$ and $\mathrm{x} 2$. Finally, the value of $\mathrm{q}(\mathrm{x} 1 \cap \mathrm{x} 2)$ is calculated and compared with the $\mathrm{q}(\mathrm{x} 1)$ and $\mathrm{q}(\mathrm{x} 2)$ to indicate the interaction types. The five interaction relationships between factor $\mathrm{x} 1$ and $\mathrm{x} 2$ are shown in Fig. 3.

\section{Results and Discussion}

According to the weight in Table 1, the TIES evaluation index of 13 prefecture-level cities in 2009, 2012, 2015 and 2018 are obtained by using the formula (7-10). The evaluation index of TI, IU, EE and CCD are calculated respectively. In order to make the comparisons of different areas and years more vivid and evident, geographic information system (GIS) is applied to analyze the spatio-temporal differentiation characteristics. Meanwhile, the geo-detector is used to explore the determinants of CCD in TIES.

\section{Spatio-Temporal Differentiation Characteristics of TI}

Fig. 4 presents the spatio-temporal differentiation characteristics of TI in Jiangsu Province. In general, it shows a cascade distribution from south to north in space and presented a continuous growth trend. From 2009 to 2012, the speed of technological innovation was very slow, leading to the spatial distribution of TI remained unchanged. In 2015, the TI in Wuxi and Nantong declined approximately $21 \%$. In 2018, middle Jiangsu and southern Jiangsu presented a big increase, indicating that the level of technological innovation achieved fast growth. Among which, Suzhou always maintained the forefront with the average value of 0.358. It had obvious advantages comparing with other regions. On the contrary, the lowest average value $(0.007)$ was in Suqian. This phenomenon can be explained from two aspects. On one hand, Suzhou has the most developed economy and the government attaches importance on technological innovation. On the other hand, the high weight of internal expenditure on R\&D (0.096) and the number of scientific papers (0.098), which has the great impact on the evaluation of technological innovation. In 2018, the internal expenditure on $R \& D$ and the number of scientific papers of Suzhou were 14.68 and 103.19 times of Suqian, respectively. In summary, there is a big gap in the spatial distribution of TI value, which manifests

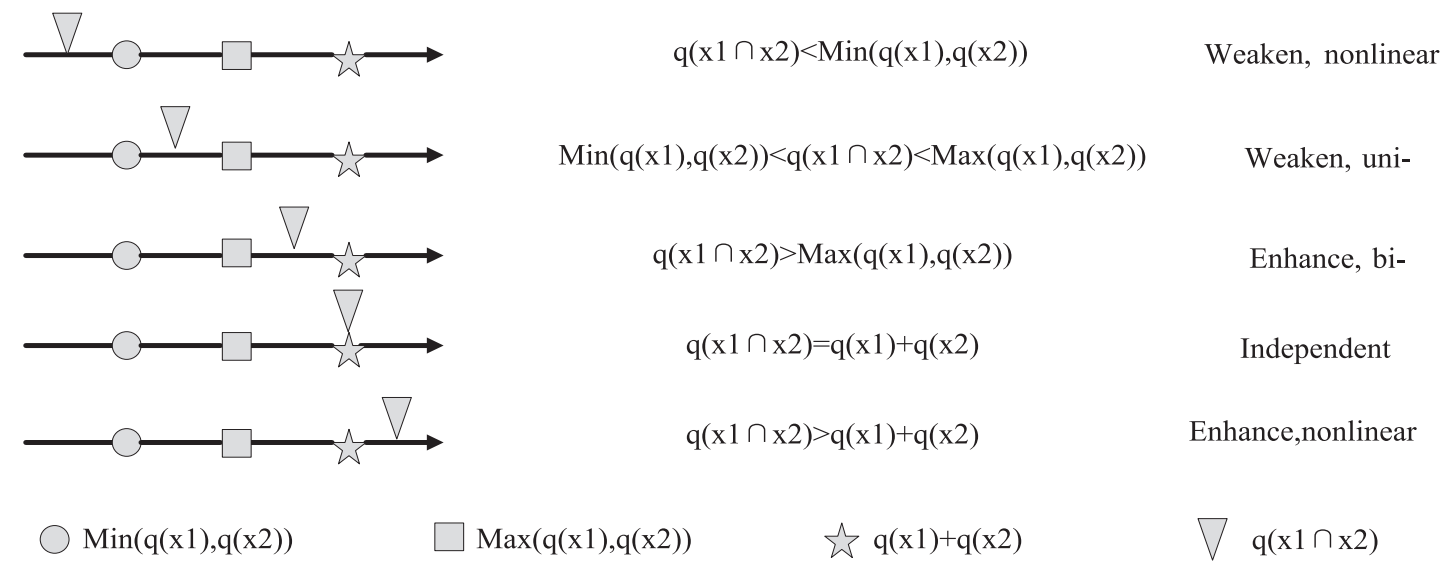

Fig. 3. Interaction relationships. 
a)
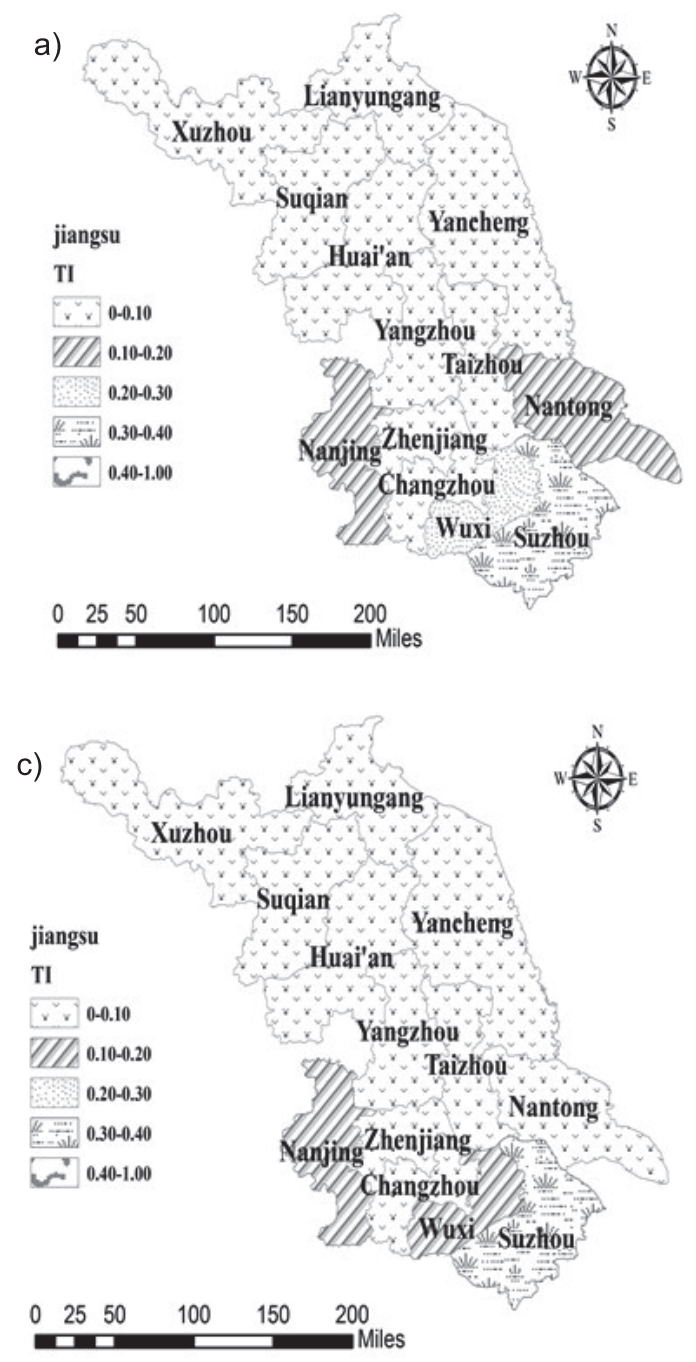
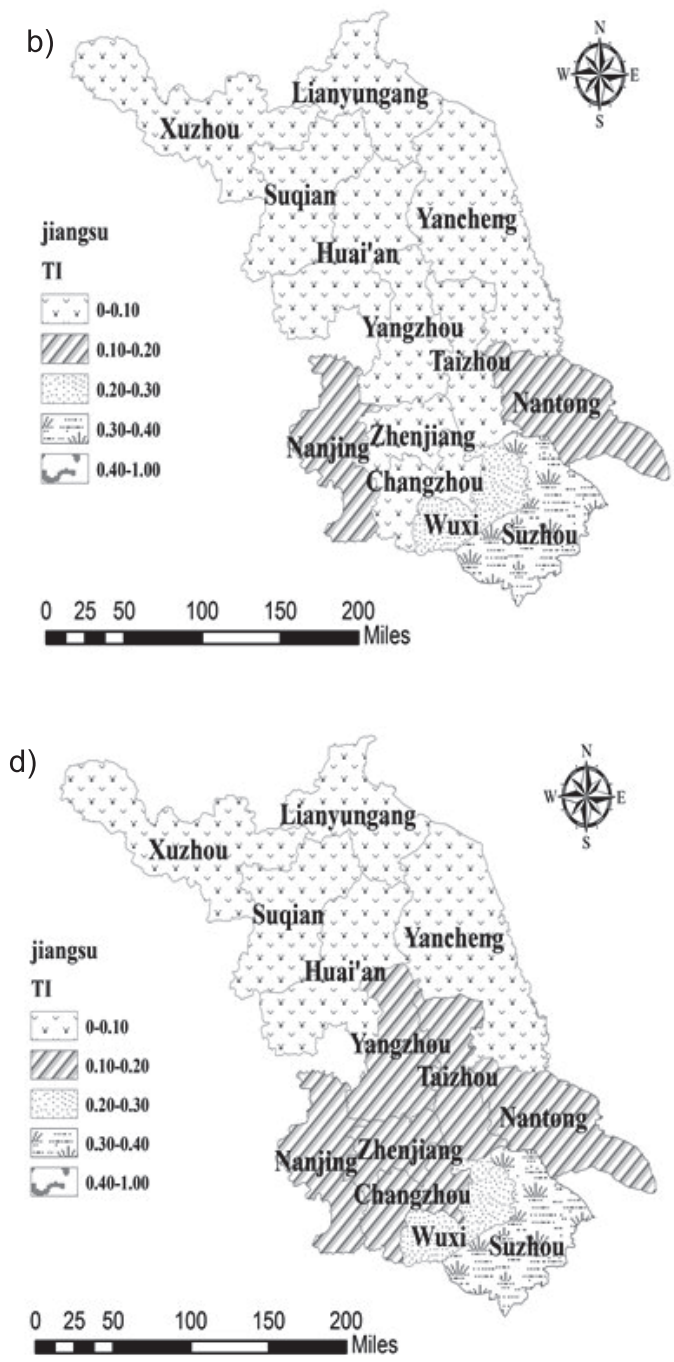

Fig. 4. Spatio-temporal differentiation characteristics of TI in a) 2009, b) 2012, c) 2015, d) 2018 in Jiangsu Province.

that southern Jiangsu is superior to middle Jiangsu than northern Jiangsu.

\section{Spatio-Temporal Differentiation Characteristics of IU}

From the perspective of IU, northern and southern Jiangsu are higher than middle Jiangsu, and it presents a continuing upward trend (Fig. 5). In 2009, the average value of IU was 0.114. Among which, Suzhou had the highest value (0.161). In 2012, the IU value declined in several cities such as Suzhou, Yancheng, Lianyungang, and Zhenjiang. Nanjing had the highest value $(0.163)$ while Yangzhou had the lowest value (0.074). In 2015, the values of IU in most cities increased obviously, for instance, Xuzhou, Suzhou, and Suqian etc. The reason is that, these cities began to emphasize the production efficiency and constantly adjusted the industrial structure, which vigorously developed new industries such as high-end equipment manufacturing, service industries and new energy and materials. In 2018, middle Jiangsu and southern Jiangsu increased significantly, indicating that the level of industrial upgrading achieved growth at an amazing rate. This suggests that middle and southern Jiangsu ought to continuously promote industrial upgrading and focus more on the high-quality production. In conclusion, most cities have reached the decent level except Yancheng. Additionally, the level of industrial upgrading in southern and middle Jiangsu is higher than that in northern Jiangsu.

\section{Spatio-Temporal Differentiation Characteristics of EE}

It showed that the overall trend in ecological environment declined from 2009 to 2018 (Fig. 6), the average value of EE decreased from 0.184 to 0.150 . In 2009, the value of EE in Yangzhou was highest (0.251) and Nanjing was the lowest (0.098). From 2012 to 2015, the level of ecological environment increased gradually except for Suzhou. In 2018, EE decreased sharply. The most obvious was Suzhou, which declined significantly from 0.154 to 0.043 during the study period. The phenomenon of "EE lagged" in southern Jiangsu contraries to $\mathrm{Li}$ et al.'s view that the regions with a developed economy have better performance 

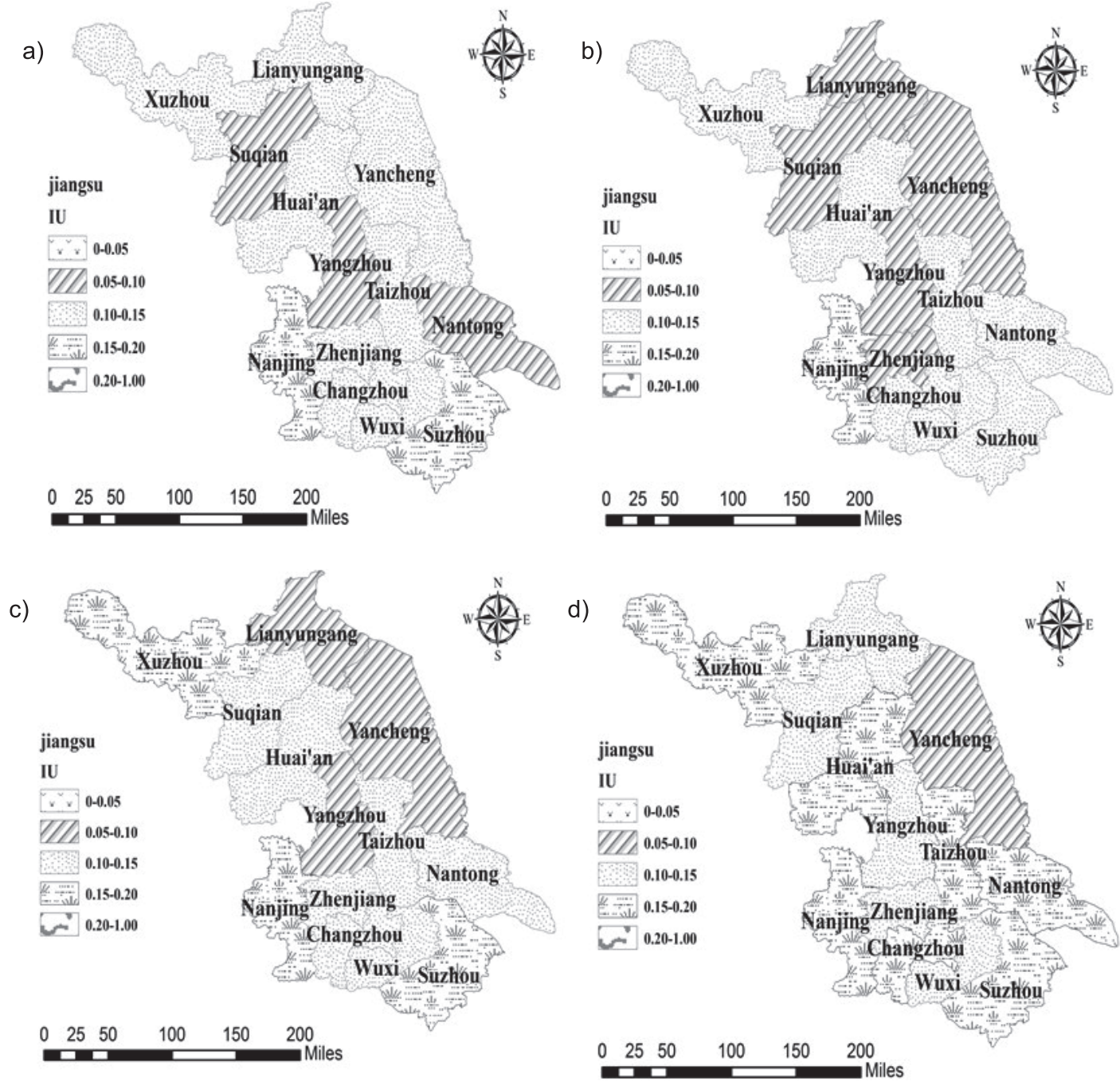

Fig. 5. Spatio-temporal differentiation characteristics of IU in a) 2009, b) 2012, c) 2015, d) 2018 in Jiangsu Province.

on ecological construction [51]. It may be caused by dense population, a great deal of pollution emission and energy consumption in Suzhou. Thus, it is imperative to take measures to limit the population and pollution according to Suzhou's ecological environment state. In a word, the level of ecological environment in middle Jiangsu was higher than that in northern and southern Jiangsu. Obviously, southern Jiangsu achieved high level of economy at the expense of ecological environment.

\section{Spatio-Temporal Differentiation Characteristics of CCD}

According to formula (8-10), the CCD can be obtained. The higher value, the higher the coordinated level of TIES. The spatio-temporal differentiation characteristics of CCD in Jiangsu Province are presented in Fig. 7.

On the basis of the evaluation standard of CCD in TIES (Table 3), Jiangsu Province is in a state of imbalance (0.2 0.4). Among which, southern and middle Jiangsu are in the mild imbalance stage, northern Jiangsu changes from moderate imbalance to mild imbalance. For southern Jiangsu, its development is stable but declining during the inspection period. For example, Suzhou and Wuxi reduce from adjacent imbalance $(0.4 \sim 0.49)$ to mild imbalance $(0.3 \sim 0.39)$. In addition, coupling coordination characteristic in southern Jiangsu is basic imbalance from "IU lagged" to "EE lagged", which indicates that the disharmony of TIES in southern Jiangsu is mainly due to the backward level of industrial upgrading at the beginning period. With the rapid development of economy, the main cause is involved into the destruction of ecological environment. On the contrary, the CCD in middle Jiangsu and northern Jiangsu display the growth trend, indicating that the coordinated level of TIES increases gradually. However, their coupling coordination characteristic are both "TI lagged", which implies that for middle and northern Jiangsu, the level of technological innovation is still in low phase so as to restrain the coordinated development of TIES. Therefore, more effective measures should be taken to strengthen technological innovation in middle and northern Jiangsu. 

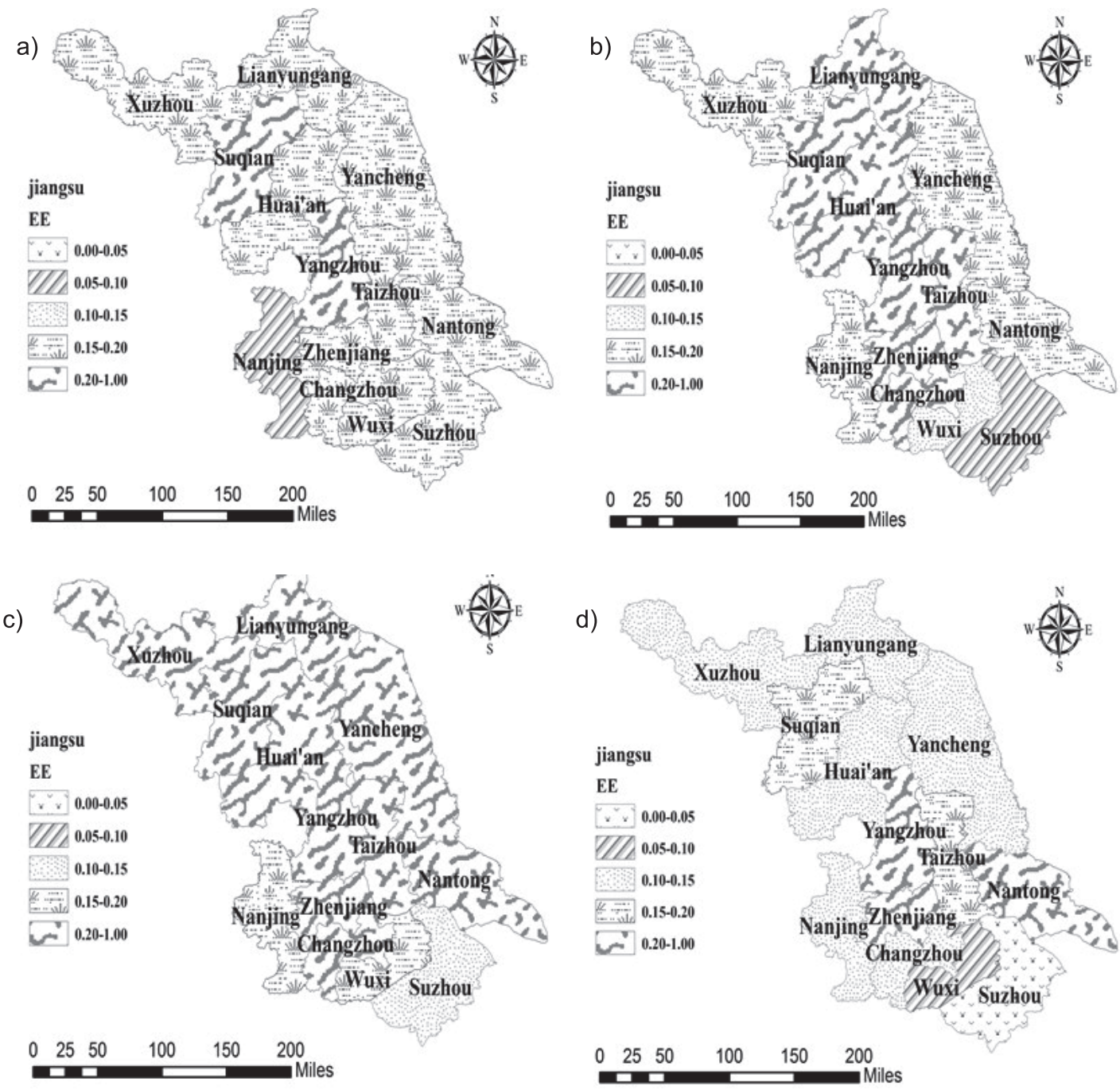

Fig. 6. Spatio-temporal differentiation characteristics of EE in a) 2009, b) 2012, c) 2015, d) 2018 in Jiangsu Province.

\section{Main Driving Factors}

\section{The Analysis of Factor Detector}

Using the factor detector method, we quantitatively analyze the influence degree of each factor on the change of CCD. It can be seen from Table 4 that the range of $q$ value is $(0.025,0.936)$, and the six factors ranked in descending order as follows: economic benefits (0.936), performance output of technological innovation (0.704), input of technological innovation resources $(0.590)$, response $(0.366)$, industrial structure optimization (0.263), pressure (0.196), industrial structure rationalization $(0.161)$, state $(0.025)$. The economic benefits have the greatest influence on $\mathrm{CCD}$, which implies that benign economic condition is a prerequisite for the coordinated development of TIES. Besides, performance output and input of technological innovation are both crucial factors, indicating that technological innovation subsystem plays a more vital role in maintaining the coordinated development of TIES compared with other two subsystems. In contrary, state and response are found to have the lowest $q$ values, reflecting that the influential degree of ecological environment subsystem is relatively smaller and is not as significant as technological innovation. Furthermore, it has a smaller contributory effect to CCD than industrial upgrading.

\section{The Analysis of Interaction Detector}

The data presents in Table 5 reveals that the degree of influence on CCD between two factors is higher than a single factor. This reflects that each factor has a positive effect on CCD. Furthermore, there is obvious synergistic effect in TIES. For instance, the interaction between $T_{2}(0.704)$ and $E_{2}(0.025)$ results in a higher combined $q$ value (0.992) comparing with other factors. This suggests that the spatial response relationship between performance output of technological innovation and state has the most significant heterogeneity. Consequently, the $q$ value achieves the highest level after spatial zoning. In addition, the $q$ values of $I_{1}(0.161)$ and state $E_{2}(0.025)$ are lowest, 
a)

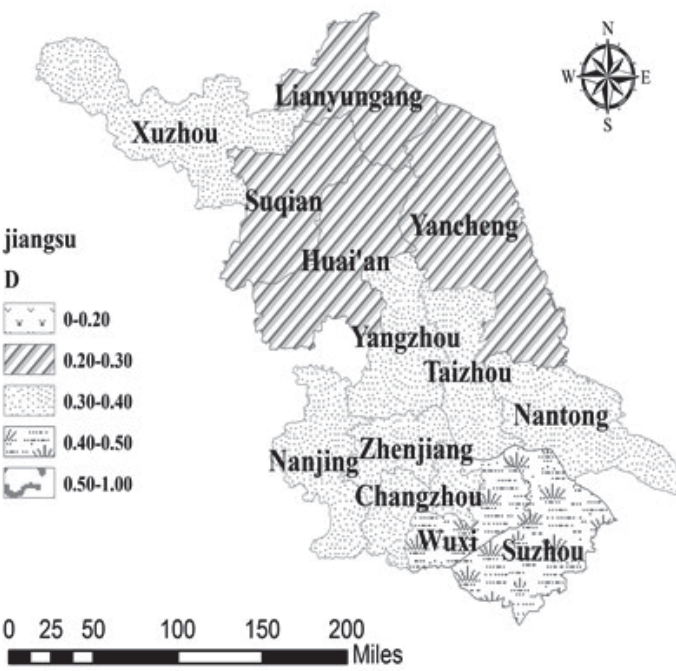

b)

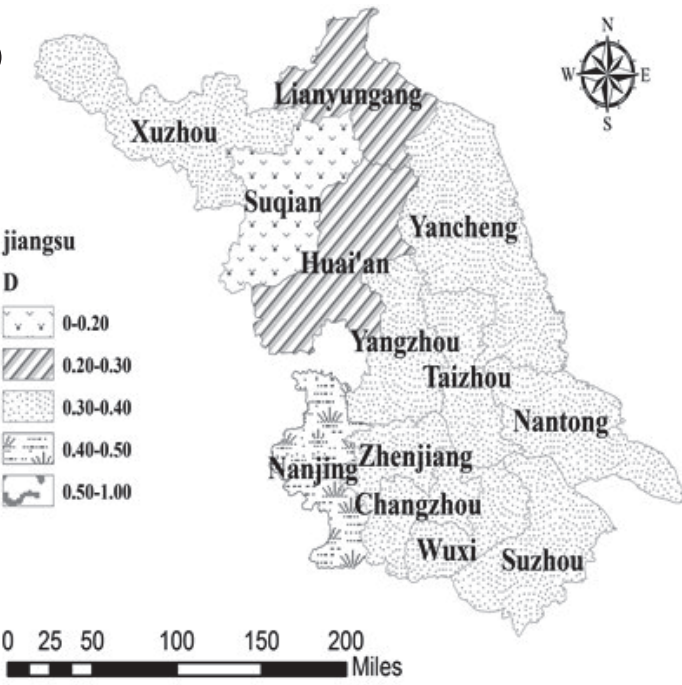

c)

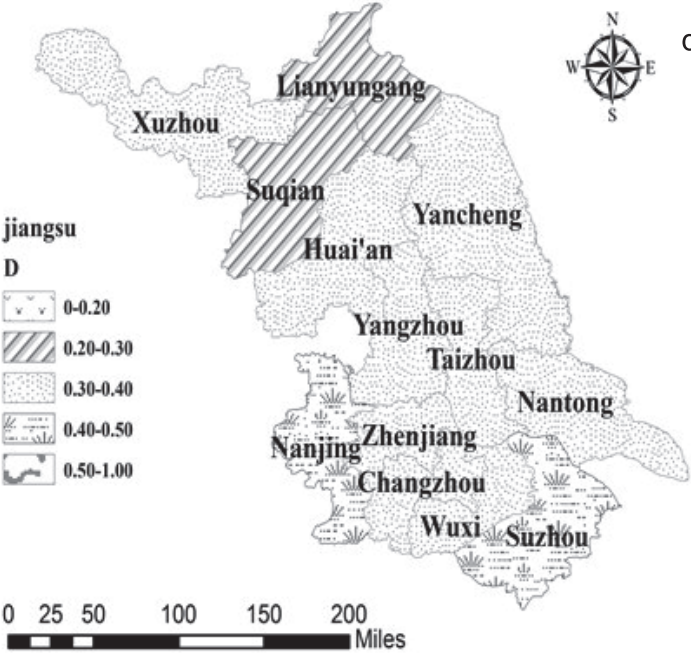

d)

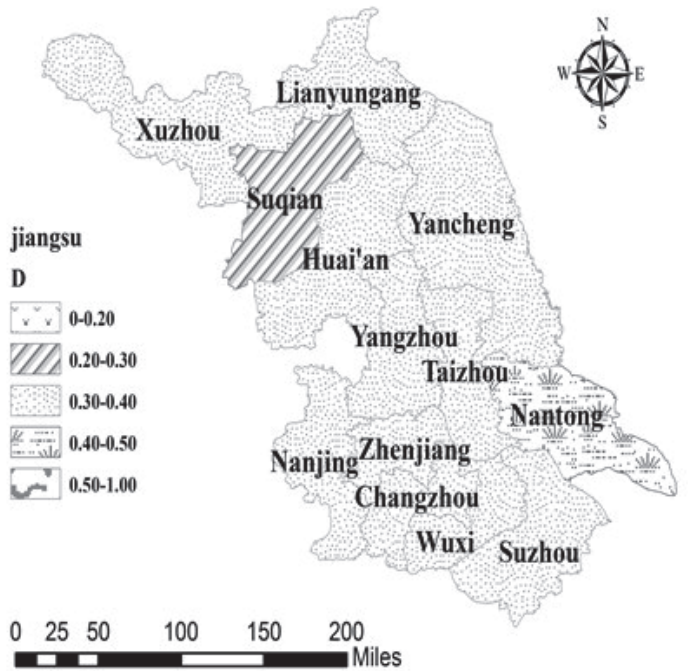

Fig. 7. Spatio-temporal differentiation characteristics of CCD in a) 2009, b) 2012, c) 2015, d) 2018 in Jiangsu Province.

upon they are superposition with each other, there is a non-linear increase in the combined $q$ value (0.357). It shows that the interaction between industrial upgrading and ecological environment can result in the improvement of CCD. Specially, industrial structure rationalization is conducive to optimizing allocation of natural resources. It also emphasizes that alleviating the stress of economic activities on ecological environment. This is consistent with the theoretical explanation in Fig. 2. Besides, the $q$ value of ecological environment subsystem is low, upon it is superposition with other two subsystem, the combined $q$ value can be significantly advanced.

Based on the above analysis, we can conclude that the CCD in southern Jiangsu is in the mild imbalance stage as well as the coupling coordination characteristic is basic imbalance, and converts from "IU lagged" to "EE lagged". According to the interaction mechanism of TIES and given that southern Jiangsu is superior to middle Jiangsu than northern Jiangsu in TI value, the critical reason for low level of CCD is the failure of enhancing the efficiency of input and output conversion in taking advantage of technological innovation. As a result, southern Jiangsu has the difficulty in promoting the adjustment and optimization of traditional industrial structure. In addition, technological innovation fails to provide technical support for production equipment. Therefore, the traditional mode of "end-treatment" still exists, which causes the decline of the ecosystem transmission efficiency.

Conversely, the coupling coordination characteristics in middle and northern Jiangsu are basic imbalance with "TI lagged". This proves that they are in a large shortage of internal expenditure on $\mathrm{R} \& \mathrm{D}$, which has relatively high contribution rate to technological innovation performance output [52]. Considering that they have the advantage of ecological environment, which is the basic guarantee of technological innovation and industrial upgrading. However, this goodness has not been utilized efficiently. Additionally, industrial advancement and industrial rationalization have not been informed in these areas [53]. On one hand, unbalanced development inhibits Jiangsu's industrial transformation and upgrading [54]. On the other hand, 
Table 3. Coupling coordination characteristics of TIES.

\begin{tabular}{|c|c|c|c|}
\hline \multicolumn{4}{|c|}{ Southern Jiangsu } \\
\hline Year & D & Subtype & Characteristics \\
\hline 2009 & 0.387 & Mild imbalance & Basic imbalance with IU lagged \\
\hline 2012 & 0.372 & Mild imbalance & Basic imbalance with IU lagged \\
\hline 2015 & 0.388 & Mild imbalance & Basic imbalance with IU lagged \\
\hline 2018 & 0.379 & Mild imbalance & Basic imbalance with EE lagged \\
\hline \multicolumn{4}{|c|}{ Middle Jiangsu } \\
\hline Year & D & Subtype & Characteristics \\
\hline 2009 & 0.334 & Mild imbalance & Basic imbalance with TI lagged \\
\hline 2012 & 0.337 & Mild imbalance & Basic imbalance with TI lagged \\
\hline 2015 & 0.374 & Mild imbalance & Basic imbalance with TI lagged \\
\hline 2018 & 0.393 & Mild imbalance & Basic imbalance with TI lagged \\
\hline \multicolumn{4}{|c|}{ Northern Jiangsu } \\
\hline Year & D & Subtype & Characteristics \\
\hline 2009 & 0.264 & Moderate imbalance & Serious imbalance with TI lagged \\
\hline 2012 & 0.269 & Moderate imbalance & Serious imbalance with TI lagged \\
\hline 2015 & 0.318 & Mild imbalance & Basic imbalance with TI lagged \\
\hline 2018 & 0.303 & Mild imbalance & Basic imbalance with TI lagged \\
\hline
\end{tabular}

Table 4. The q value of driving factors.

\begin{tabular}{|c|c|c|c|}
\hline Factors & Q value & Factors & Q value \\
\hline Resources input of technological innovation $\left(\mathrm{T}_{1}\right)$ & 0.590 & Economic benefits $\left(\mathrm{I}_{3}\right)$ & 0.936 \\
\hline Performance output of technological innovation $\left(\mathrm{T}_{2}\right)$ & 0.704 & Pressure $\left(\mathrm{E}_{1}\right)$ & 0.196 \\
\hline Industrial structure rationalization $\left(\mathrm{I}_{1}\right)$ & 0.161 & State $\left(\mathrm{E}_{2}\right)$ & 0.025 \\
\hline Industrial structure optimization $\left(\mathrm{I}_{2}\right)$ & 0.263 & Response $\left(\mathrm{E}_{3}\right)$ & 0.366 \\
\hline
\end{tabular}

Table 5. Results of interaction detection.

\begin{tabular}{|c|c|c|c|c|c|c|c|c|}
\hline Factors & $\mathrm{T}_{1}$ & $\mathrm{~T}_{2}$ & $\mathrm{I}_{1}$ & $\mathrm{I}_{2}$ & $\mathbf{I}_{3}$ & $\mathbf{E}_{\mathbf{1}}$ & $\mathbf{E}_{\mathbf{2}}$ & $\mathbf{E}_{\mathbf{3}}$ \\
\hline $\mathrm{T}_{1}$ & 0.590 & & & & & & & \\
\hline $\mathrm{T}_{2}$ & 0.783 & 0.704 & & & & & & \\
\hline $\mathrm{I}_{1}$ & 0.638 & 0.799 & 0.161 & & & & & \\
\hline $\mathrm{I}_{2}$ & 0.828 & 0.929 & $\mathbf{0 . 8 2 6}$ & 0.263 & & & & \\
\hline $\mathrm{I}_{3}$ & 0.997 & 0.982 & 0.988 & 0.981 & 0.936 & & & \\
\hline $\mathrm{E}_{1}$ & $\mathbf{0 . 8 2 2}$ & 0.897 & $\mathbf{0 . 3 7 8}$ & $\mathbf{0 . 4 6 2}$ & 0.988 & 0.196 & & \\
\hline $\mathrm{E}_{2}$ & $\mathbf{0 . 9 6 7}$ & $\mathbf{0 . 9 9 2}$ & $\mathbf{0 . 3 5 7}$ & $\mathbf{0 . 6 2 5}$ & 0.945 & $\mathbf{0 . 3 5 7}$ & 0.025 & \\
\hline $\mathrm{E}_{3}$ & 0.788 & 0.891 & $\mathbf{0 . 7 9 2}$ & 0.426 & 0.960 & 0.523 & $\mathbf{0 . 8 0 1}$ & 0.366 \\
\hline
\end{tabular}

Note: Bold figures denote the enhanced non-linear interaction between two factors. 
there is a great difference between the regions in Jiangsu Province, and all kinds of elements cannot be allocated rationally.

In this study, the evaluation method used here may have several shortfalls such as incomplete indicators due to the limited data available. Additionally, considering the particularities of different areas, future studies need to expand by including more provinces to establish a comprehensive model for explaining the coupling coordination relationship of TIES.

\section{Conclusions}

This study employs the coupling coordination model to calculate the CCD in TIES in Jiangsu Province. Then we analyze its spatio-temporal differentiation characteristics. Furthermore, to extend and enrich the study, a geo-detector model is used to explore the determinants of CCD. We reach the conclusions as follows.

The number of scientific papers, improved Theil Index and per capita area of park green areas have the significantly effect on the evaluation of technological innovation, industrial upgrading and ecological environment, respectively.

In terms of time series, the CCD in Jiangsu Province presents a slight growth with fluctuation from 0.329 to 0.354 , indicating that the level of coupling coordination is in the stage of mild imbalance. The relationship among three subsystems is not harmonious even slight antagonistic. Specifically, TI and UI present a continuous growth trend whereas the value of EE displays a declined trend, meaning that the backwardness of ecological environment is the bottleneck for coordination development.

From the perspective of spatial pattern, three regions have obvious differences. Specifically, TI shows a cascade distribution from south to north in space; with regard to the value of IU, northern and southern Jiangsu are both higher than middle Jiangsu; in terms of $\mathrm{EE}$, middle Jiangsu is superior to northern Jiangsu than southern Jiangsu. In addition, the disharmony of TIES in southern Jiangsu is mainly due to the backward level of industrial upgrading at the beginning period. Then it involves to the destruction of ecological environment. While the reason for basic imbalance in middle Jiangsu and northern Jiangsu is the poor level of technological innovation.

The economic benefits (belonging to TI subsystem) have been the most significant factor of CCD. On the contrary is state (belonging to EE subsystem). Meanwhile, the superposition of the two factors results in a "enhance, bilinear" even "enhance, nonlinear" effect. In particular, the $q$ value of each factor in ecological environment subsystem can be significantly improved upon it is superposed with other factors. This verifies that the interaction of three subsystems can effectively promote the improvement of CCD in TIES.

In the light of above analysis, it can be known that the current CCD of TIES is not satisfactory, in order to promote the coordinated development of TIES and achieve the goal of management from "end control" to "source control" in Jiangsu Province, efforts must be exerted in time. Hence, the government should focus on technological breakthroughs, constantly introduce new equipment and optimize production technology. At the same time, high pollution and extensive industries must be strictly limited. Middle and northern Jiangsu should continuously increase innovation investment, encourage independent research and development and create a good environment for technological innovation.

Based on the analyses of geo-detector, the economic benefits have the greatest influence on CCD and the degree of influence between two factors is higher than a single factor. Thus, the government should advocate high-quality economic development and balance the relationship among three subsystems. Meanwhile, Jiangsu should form a new comprehensive mechanism of strengthening technological innovation, promoting industrial upgrading, alleviating the pressure of environment and the interactions as well as mutual promotions of the three.

In addition, based on the current situation of obvious gap in Jiangsu Province, various transportation systems and the degree of marketization ought to be ameliorated. Then resources and talents can flow quickly and allocate optimally. Consequently, regional advantages can be obtained. Finally, actions and endeavours ought to be unified, then an organic system and virtuous circle of mutual promotion among technological innovation, industrial upgrading and ecological environment can be formed.

\section{Acknowledgements}

This research was supported by the Key Projects of Soft Science Research in Shanghai with the title "Research on Radiation Effect and Countermeasure of Shanghai Science and Technology Creation Center under the Integration Strategy of Yangtze River Delta" (No.19692108000).

\section{Conflict of Interest}

The authors declare no conflict of interest.

\section{References}

1. LIU Q.L.,WANG Q. How China achieved its 11th FiveYear Plan emissions reduction target: A structural decomposition analysis of industrial $\mathrm{SO}_{2}$ and chemical oxygen demand. Sci. Total Environ., 574, 1104, 2017.

2. Jiangsu Provincial Bureau of Statistics. Statistical Bulletin on National Economic and Social Development of Jiangsu Province. Available online: http://www.js.gov. 
cn/art/2020/3/3/art 34151 8994782.html (accessed on $3^{\text {rd }}$ March, 2020).

3. TAO S., TIAN W.T., WEI Z.,QIAN Z.Spatiotemporal Relationship Between Ecological Environment and Economic Development in Tropical and Subtropical Regions of Asia. Tropical Conservation Science, 12, 1, 2019.

4. Department of Ecology and Environment of Jiangsu Province. Jiangsu Province Annual Bulletin of Ecoenvironmental Conditions. Available online: http://hbt. jiangsu.gov.cn/art/2019/4/30/art_1649_8323758.html (accessed on $30^{\text {th }}$ April, 2019).

5. DONG F.,WANG Y., ZHENG L.,LI J.Y.,XIE S.X. Can industrial agglomeration promote pollution agglomeration? Evidence from China. J. Clean. Prod., 246, 118960, 2020.

6. SONG M., WANG S. Market competition, green technology progress and comparative advantages in China. Management Decision, 56 (1), 188, 2018.

7. WANG S., SONG J.N., WANG X.E., YANG W. The Spatial and Temporal Research on the Coupling and Coordinated Relationship between Social Economy and Energy Environment in the Belt and Road Initiatives. Sustainability, 11 (2), 407, 2019.

8. CUI D., CHEN X., XUE Y.L., LI R., ZENG W.H. An integrated approach to investigate the relationship of coupling coordination between social economy and water environment on urban scale - A case study of Kunming. J. Environ. Manage., 234, 189, 2019.

9. DONG F., LI J.Y., WANG Y., ZHANG X.Y., ZHANG S.N., ZHANG S.Q. Drivers of the decoupling indicator between the economic growth and energy-related $\mathrm{CO}_{2}$ in China: A revisit from the perspectives of decomposition and spatiotemporal heterogeneity. Sci. Total Environ., 685, 631, 2019.

10. YANG X.P., ZHANG D.C., JIA Q.Q., ZHANG W.T., WANG T.Y. Exploring the Dynamic Coupling Relationship between Agricultural Economy and Agro-Ecological Environment in Semi-Arid Areas: A Case Study of Yulin, China. Sustainability, 11 (8), 2259, 2019.

11. XU M., CHEN C., DENG X. Systematic analysis of the coordination degree of China's economy-ecological environment system and its influencing factor. Environmental science and pollution research, 26, 29722, 2019.

12. YAO L., LI X.L., LI Q., WANG J.K. Temporal and Spatial Changes in Coupling and Coordinating Degree of New Urbanization and Ecological-Environmental Stress in China. Sustainability, 11 (4), 1171, 2019.

13. DING L., ZHAO W.T., HUANG Y.L., CHENG S.G., LIU C. Research on the Coupling Coordination Relationship between Urbanization and the Air Environment: A Case Study of the Area of Wuhan. Atmosphere, 6, 1539, 2015.

14. FANG C.L., ZHOU C.H., GU C.L., CHEN L.D., LI S.C. Theoretical analysis of interactive coupled effects between urbanization and eco-environment in mega-urban agglomerations. Acta Geogr. Sin., 71, 531, 2016.

15. WANG Z.B., LIANG L.W., SUN Z., WANG X.M. Spatiotemporal differentiation and the factors influencing urbanization and ecological environment synergistic effects within the Beijing-Tianjin-Hebei urban agglomeration. J. Environ. Manage., 243, 227, 2019.

16. LIU N., LIU C., XIA Y., DA B. Examining the coordination between urbanization and eco-environment using coupling and spatial analyses: A case study in China. Ecological Indicators, 93, 1163, 2018.
17. NGAI L.R., PISSARIDES C.A. Structural Change in a Multisector Model of Growth Amer. Econ. Rev., 97, 429, 2007.

18. DING X.H., ZHANG Z.X., WU F.P., XU X.Y. Study on the Evolution of Water Resource Utilization Efficiency in Tibet Autonomous Region and Four Provinces in Tibetan Areas under Double Control Action. Sustainability, 11 (12), 3396, 2019.

19. ANWAR K., FAQIR M., YANG C.G., JAMAL H., SADIA B., MUHAMMAD A.K. The impression of technological innovations and natural resources in energy-growthenvironment nexus: A new look into BRICS economies. Science of The Total Environment, 727, 138265, 2020.

20. MICHAEL E.P., CLAAS V.D.L. Toward a New Conception of the Environment-Competitiveness Relationship. J. Econ. Perspect., 9, 97, 1995.

21. JAFFE A.B., PALMER K. Environmental Regulation and Innovation: A Panel Data Study. Review of Economics Statistics, 79 (4), 610, 1997.

22. LIN B.Q., ZHU J.P. Determinants of renewable energy technological innovation in China under $\mathrm{CO}_{2}$ emissions constraint. J. Environ. Manage., 247, 662, 2019.

23. RAMAKRISHNAN R., ANDREW B., PRITHWIRAJ N., LUC M. Impact of environmental regulations on innovation and performance in the UK industrial sector. Management Decision, 48, 1493, 2010.

24. GRAY W.B. The Cost of Regulation: OSHA, EPA and the Productivity Slowdown. Amer. Econ. Rev., 77, 998, 1987.

25. LI H., HE F., DENG G. How does Environmental Regulation Promote Technological Innovation and Green Development? New Evidence from China. Polish Journal of Environmental Studies, 29, 689, 2020.

26. SUN W., LI W.H., TANG Z.P., FAN J. Industrial structure optimization in central China under the energy constraint. Journal of Geographical Sciences, 26, 1377, 2016.

27. LI W.W., WANG W.P., WANG Y., QIN Y.B. Industrial structure, technological progress and $\mathrm{CO}_{2}$ emissions in China: Analysis based on the STIRPAT framework. Nat. Hazards, 88, 1545, 2017.

28. LI L.G., ZHANG P.Y., LIU W.X., LI J., WANG L.F. Spatial-temporal evolution characteristics and influencing factors of county-scale environmental pollution in Jilin Province, Northeast China. The journal of applied ecology, 30, 2361, 2019.

29. ZHOU X.Y., LEI K., MENG W., KHU S.T. Industrial structural upgrading and spatial optimization based on water environment carrying capacity. J. Clean. Prod., 165, 1462, 2017.

30. ZHAO X. The Eco-environment Effect of the Industrial Spatial Structure in Gansu. The journal of Arid Land Resources and Environment, 21 (6), 17, 2007.

31. DONG F., LI J.Y., LI K.,SUN Z.Y., YU B.L., WANG Y., ZHANG S.N. Causal chain of haze decoupling efforts and its action mechanism: Evidence from 30 provinces in China, J. Clean. Prod., 245, 118889, 2020.

32. CHEN Y., ZHAO L. Exploring the relation between the industrial structure and the eco-environment based on an integrated approach: A case study of Beijing, China. Ecol. Indicators, 103, 83,2019.

33. GHISELLINI P., CIALANI C., ULGIATI S. A review on circular economy: the expected transition to a balanced interplay of environmental and economic systems. J. Clean. Prod., 114, 11,2016.

34. SHI L.L., ZHAO J. Environmental regulation, technological innovation and industrial structure 
upgrading. Science Research Management, 39 (1), 119, 2018.

35. KLEPPER S. Firm Survival and the Evolution of Oligopoly. RAND J. Econ., 33, 37, 2002.

36. CHEN Q.Q., FANG B., DOU X.C., LIU J.W. Measurement and economic effects of industrial transformation and upgrading in Gansu Province. Arid Land Geography, 39, 1365, 2016.

37. WANG X.J., ZHU Q. Science and Technology Innovation Promotes the Development of City-Industry Integration in Resource-based Cities: a Logical Framework. Proceedings of the 2018 International Conference on Energy Development and Environmental Protection, 174, 72, 2018.

38. GU G.T., XU B. Innovation Path of Manufacturing Enterprises and Strategies for Transformation and Upgrading in China. Journal of Advanced Computational Intelligence and Intelligent Informatics, 21 (6), 1048, 2017.

39. ZHAO C. Technological Innovation to Optimize the Industrial Structure of Manufacturing in the Pearl River Delta. Adv Mater Res, 875, 1165, 2014.

40. XU M., CHEN C., DENG X. Systematic analysis of the coordination degree of China's economy-ecological environment system and its influencing factor. Environ. Sci. Pollut. Res., 26 (29), 26722, 2019.

41. Jiangsu Bureau of Statistics. Jiangsu Statistical Yearbook 2010-2019. China Statistics Press, Beijing, 20102019.

42. REN L., CUI E., SUN H. Temporal and spatial variations in the relationship between urbanization and water quality. Environ. Sci. Pollut. Res., 21, 13646, 2014.

43. GAN C., ZHENG R., YU D. An Empirical Study on the Effects of Industrial Structure on Economic Growth and Fluctuations in China. Economic Research Journal, 21, 85, 2011.

44. HE D. X., YAO Z.Q. Effects of China's Industrial Structure Adjustment, Object of Industrial Optimization and Policy Supporting System. China Industrial Economics, 5, 46, 2008.
45. WANG G., YANG D., YE L., XIONG C. Spatial Utilization Coordination Features and Development Potential on Ecology-Agriculture-Urban Space of Key Ecological Function Areas: A Case Study of Tacheng Basin, China. Polish Journal of Environmental Studies, 29, 4361, 2020.

46. LIU W.J., JIAO F.C., REN L.J., XU X.G., WANG J.C., WANG X. Coupling coordination relationship between urbanization and atmospheric environment security in Jinan City. J. Clean. Prod., 204, 1, 2018.

47. WU J., LUO J.M., TANG L. Coupling Relationship between Urban Expansion and Lake Change-A Case Study of Wuhan. Water, 11 (6), 2019.

48. WANG J.F., LI X.H., CHRISTAKOS G., LIAO Y.L., ZHANG T., GU X., ZHENG X.Y. Geographical DetectorsBased Health Risk Assessment and its Application in the Neural Tube Defects Study of the Heshun Region, China. International Journal of Geographical Information Science, 24, 107, 2010.

49. WANG J., XU C. Geodetector: principle and prospective. Acta Geographica Sinica, 72, 116, 2017.

50. LIU Y., YANG Z., HUANG Y., LIU C. Spatiotemporal evolution and driving factors of China's flash flood disasters since 1949. Science China Earth Sciences, 61, 1804, 2018

51. LI C., YUAN B., ZHANG Y. Effect Assessment of Ecological Construction in China from 2008 to 2014. Polish Journal of Environmental Studies, 28, 1241, 2019.

52. WANG J.M., LI Y. Does factor endowment allocation improve technological innovation performance? An empirical study on the Yangtze River Delta region. Science of the Total Environment, 10, 716, 2020.

53. GAO X., ZHAI K.Y., QIU Y., CAO M.Q., WU M.L. Innovation Institution and Spatial Transfer of Energy Industry: The Case of Jiangsu Province, China. SAGE Open, 10, 19, 2020.

54. YANG J.B., DING H. A Quantitative Assessment of Sustainable Development Based on Relative Resource Carrying Capacity in Jiangsu Province of China. International Journal of Environmental Research and Public Health, 13, 15, 2018. 
